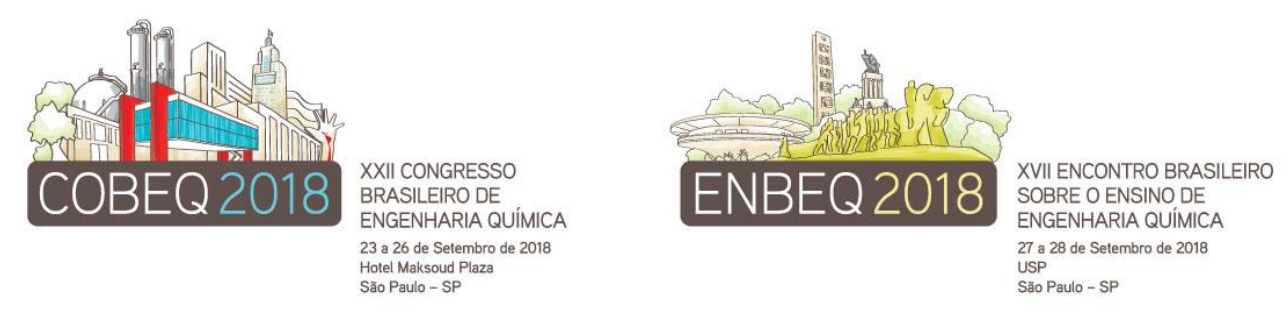

\title{
FRACIONAMENTO DE SURFACTINA EM COLUNA DE BOLHAS E ESPUMA
}

\author{
PERNA RF ${ }^{1}$, GONÇALVES MCP $^{1}$, FARIA LL ${ }^{1}$, SANTANA CC $^{2}$ \\ ${ }^{1}$ Instituto de Ciência e Tecnologia, Universidade Federal de Alfenas (UNIFAL-MG) \\ ${ }^{2}$ Faculdade de Engenharia Química, Universidade Estadual de Campinas (UNICAMP) \\ E-mail para contato: rafael.perna@unifal-mg.edu.br
}

\begin{abstract}
RESUMO - O presente trabalho teve como objetivo o estudo da separação $e$ concentração do biossurfactante surfactina, sintetizado por fermentação pela bactéria Bacillus subtilis, utilizando-se o processo de fracionamento em coluna de bolhas $e$ espuma, a fim de se otimizar o enriquecimento e a recuperação do bioproduto. $O$ processo envolve a injeção de gás nitrogênio nas vazões de 20, 40 e $60 \mathrm{~mL}^{\mathrm{m}} \mathrm{min}^{-1}$ pela base da coluna de líquido que contém a solução de surfactina nas concentrações iniciais de 240, 400 e $700 \mathrm{mg} . \mathrm{L}^{-1}$. No topo do equipamento forma-se uma coluna de espuma concentrada no biossurfactante, o qual pode ser recuperado pelo rompimento mecânico da espuma. A recuperação total de surfactina para diferentes condições experimentais variou de 80,5 a 98,3\%. O maior valor de enriquecimento foi alcançado para soluções diluídas de surfactina operando a coluna a baixa vazão de gás e com temperatura relativamente elevada. Os resultados indicaram que o processo que utiliza coluna de bolhas e espuma se mostra promissor na etapa de concentração do biossurfactante.
\end{abstract}

\section{INTRODUÇÃO}

Os surfactantes são compostos químicos amplamente utilizados na indústria por apresentarem funções e aplicações diversas (Barros et al., 2007). Os surfactantes naturais podem estar presentes no meio de cultura como solutos diluídos ou dissolvidos em baixa concentração, o que dificulta a recuperação destas moléculas anfifílicas. Um processo de separação viável capaz de recuperar tais moléculas presentes em soluções diluídas é o fracionamento em coluna de bolhas e espuma (Brown et al., 1990), cujo princípio se baseia no fenômeno da adsorção de moléculas tensoativas na interface gás-líquido (Santana, 1994). Dessa forma, este trabalho teve como objetivo estudar a separação e a concentração do biossurfactante surfactina, por meio do processo de fracionamento em coluna de bolhas e espuma operada em diferentes condições, visando otimizar o enriquecimento e a recuperação do bioproduto (surfactina) mediante aplicação de planejamento experimental.

\section{MATERIAIS E MÉTODOS}

\subsection{Surfactina}

Soluções de surfactina de Bacillus subtilis LB5a, obtidas por fermentação submersa a partir da manipueira (líquido extraído da mandioca durante o processo de fabricação da farinha), foram gentilmente cedidas pelo Laboratório de Bioaromas da Faculdade de Engenharia de Alimentos da UNICAMP nas concentrações de 240, 400 e 700 mg. $\mathrm{L}^{-1}$ em pH 7,0. 


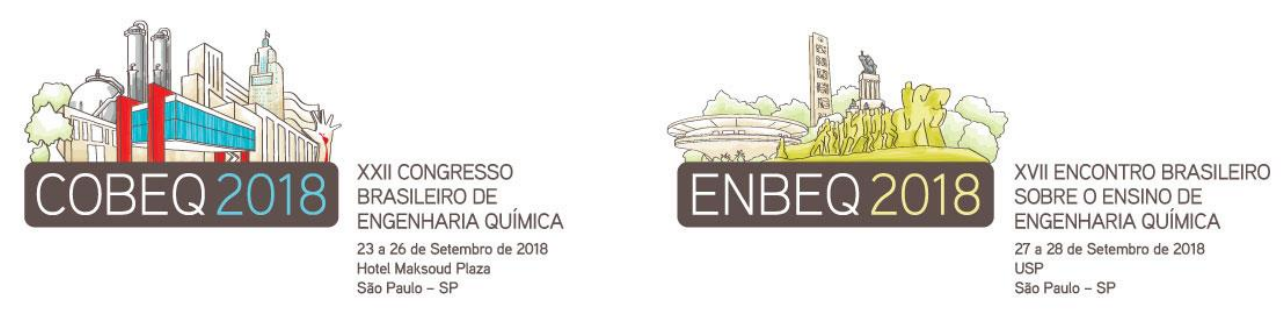

\subsection{Planejamento experimental}

Foram avaliadas, por planejamento experimental fatorial completo $2^{3}$ com replicata no ponto central, as seguintes variáveis do processo: temperatura $\left(15,25\right.$ e $\left.35^{\circ} \mathrm{C}\right)$, vazão volumétrica de gás nitrogênio $\left(20,40\right.$ e $\left.60 \mathrm{~mL} \cdot \mathrm{min}^{-1}\right)$ e concentração inicial de surfactina $\left(240,400\right.$ e $\left.700 \mathrm{mg} . \mathrm{L}^{-1}\right)$. Os ensaios realizados estão dispostos na matriz de planejamento fatorial (Tabela 1).

Tabela 1 - Matriz do planejamento fatorial completo $2^{3}$ com replicata no ponto central

\begin{tabular}{ccccccc}
\hline & \multicolumn{3}{c}{ Níveis codificados } & \multicolumn{3}{c}{ Níveis reais } \\
\cline { 2 - 7 } Ensaios & $\begin{array}{c}\text { Vazão } \\
\left(\mathrm{X}_{1}\right)\end{array}$ & $\begin{array}{c}\text { Concentração } \\
\left(\mathrm{X}_{2}\right)\end{array}$ & $\begin{array}{c}\text { Temperatura } \\
\left(\mathrm{X}_{3}\right)\end{array}$ & $\begin{array}{c}\text { Vazão } \\
(\mathrm{Q}) \\
\left(\mathrm{mL} . \mathrm{min}^{-1}\right)\end{array}$ & $\begin{array}{c}\text { Concentração } \\
\left(\mathrm{C}_{0}\right) \\
\left(\mathrm{mg}_{\mathrm{L}} \mathrm{L}^{-1}\right)\end{array}$ & $\begin{array}{c}\text { Temperatura } \\
(\mathrm{T}) \\
\left({ }^{\circ} \mathrm{C}\right)\end{array}$ \\
\hline 1 & -1 & -1 & -1 & 20 & 240 & 15 \\
2 & 1 & -1 & -1 & 60 & 240 & 15 \\
3 & -1 & 1 & -1 & 20 & 700 & 15 \\
4 & 1 & 1 & -1 & 60 & 700 & 15 \\
5 & -1 & -1 & 1 & 20 & 240 & 35 \\
6 & 1 & -1 & 1 & 60 & 240 & 35 \\
7 & -1 & 1 & 1 & 20 & 700 & 35 \\
8 & 1 & 1 & 1 & 60 & 700 & 35 \\
9 & 0 & 0 & 0 & 40 & 400 & 25 \\
10 & 0 & 0 & 0 & 40 & 400 & 25 \\
11 & 0 & 0 & 0 & 40 & 400 & 25 \\
\hline
\end{tabular}

\subsection{Operação da coluna de bolhas e espuma}

Os parâmetros de processo, monitorados durante a realização dos experimentos, foram as concentrações de surfactina nas colunas de bolhas (curvas de depleção) e de espuma, a temperatura de operação da coluna de fracionamento, a vazão volumétrica de gás nitrogênio e o produto de topo, que é o líquido gerado pela ruptura das células de espuma.

As amostras coletadas na coluna de bolhas (solução de surfactina) e espuma (produto de topo) foram quantificadas por tensiometria utilizando tensiômetro KRUSS/modelo K-12. As medidas foram feitas a $25{ }^{\circ} \mathrm{C}$ adotando-se o método do anel de Du Nouy (1919), em que se mede a força necessária para destacar um anel de platina de uma superfície líquida.

\section{RESULTADOS E DISCUSSÃO}

As Figuras 1 e 2 mostram a variação da concentração de surfactina nas colunas de bolhas (líquido) e espuma, respectivamente, em função do tempo de processo para diferentes condições. Na Figura 1 (curvas de depleção), observou-se a redução da concentração do biossurfactante em todos os casos avaliados, indicando a sua remoção do meio líquido. A remoção deve-se às maiores taxas de transferência de massa, ocasionadas por gradientes de concentração entre o seio da solução e a interface gás-líquido. Maiores taxas de redução de surfactina foram obtidas para vazões elevadas do gás, devido ao aumento das taxas de formação de área superficial gás-líquido promovido pelo maior número de bolhas de gás na coluna de líquido, favorecendo a adsorção. A área superficial das bolhas de gás é fundamental para a operação da coluna, pois a surfactina adsorve nesta região. 

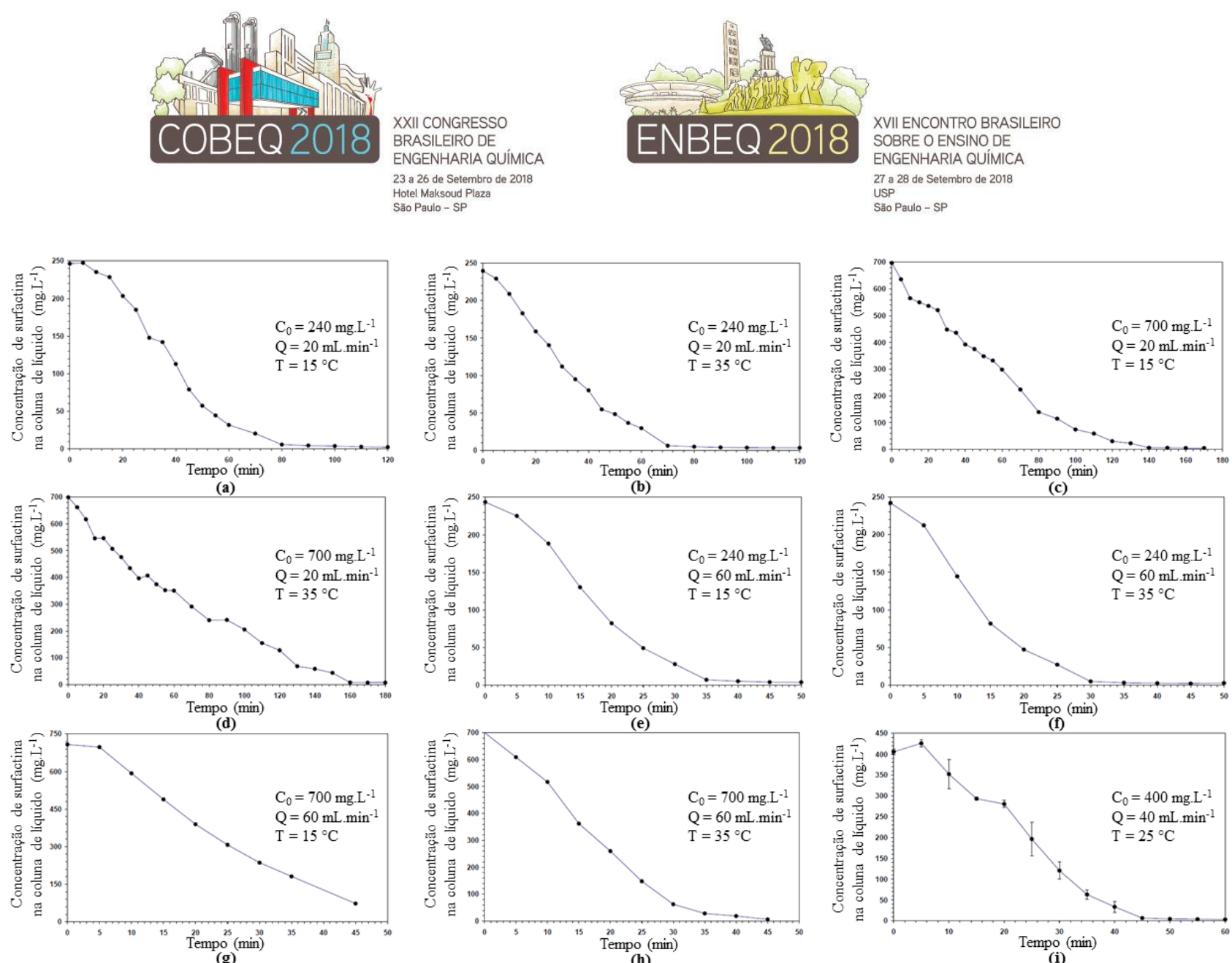

Figura 1 - Variação da concentração de surfactina na coluna de líquido em função do tempo de processo (curvas de depleção).
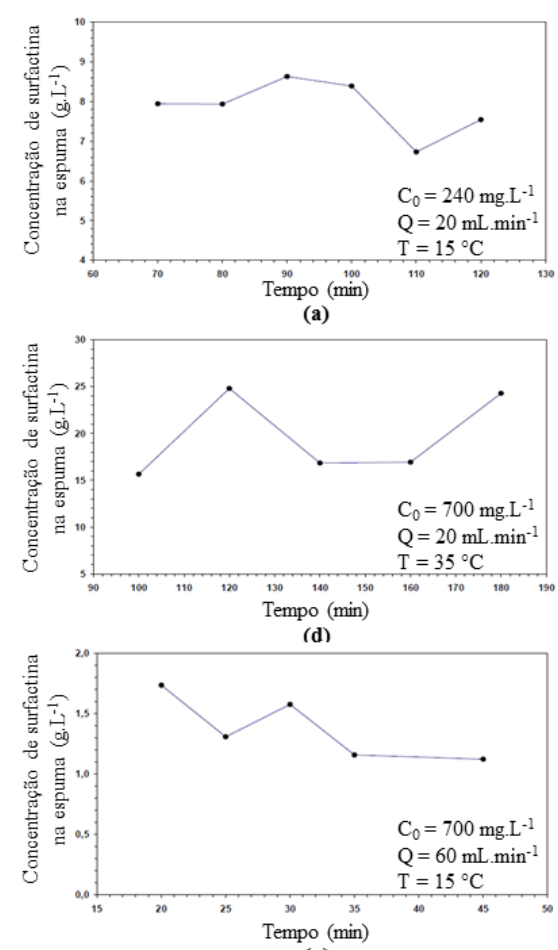

(g)

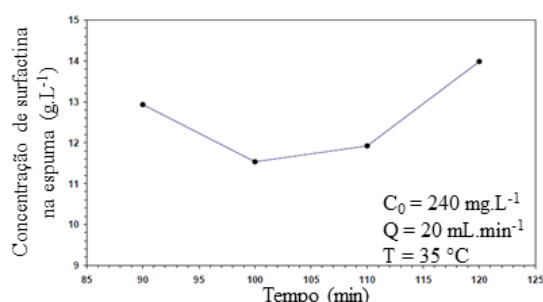

(b)

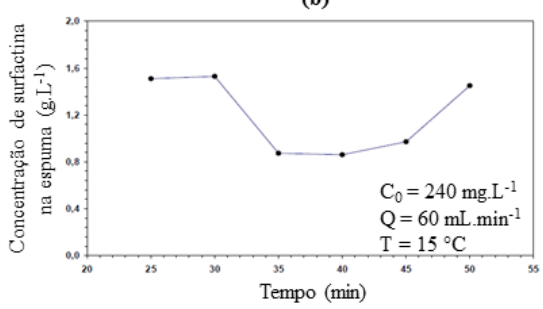

(e)

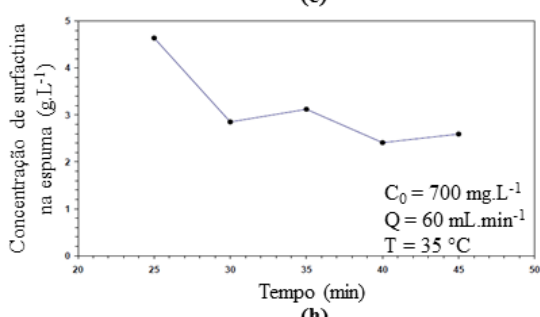

(h)

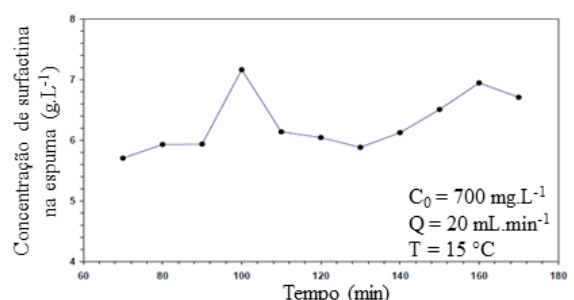

(c)

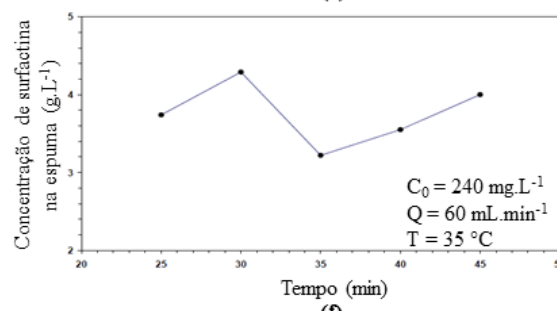

(f)

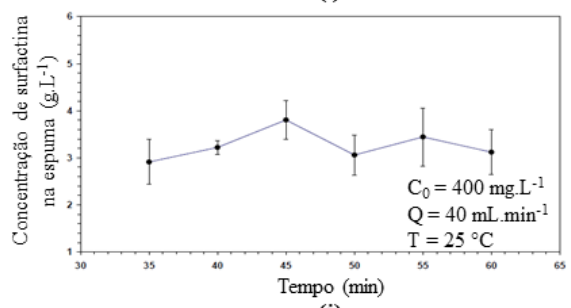

(i)

Figura 2 - Variação da concentração de surfactina na espuma em função do tempo de processo. 

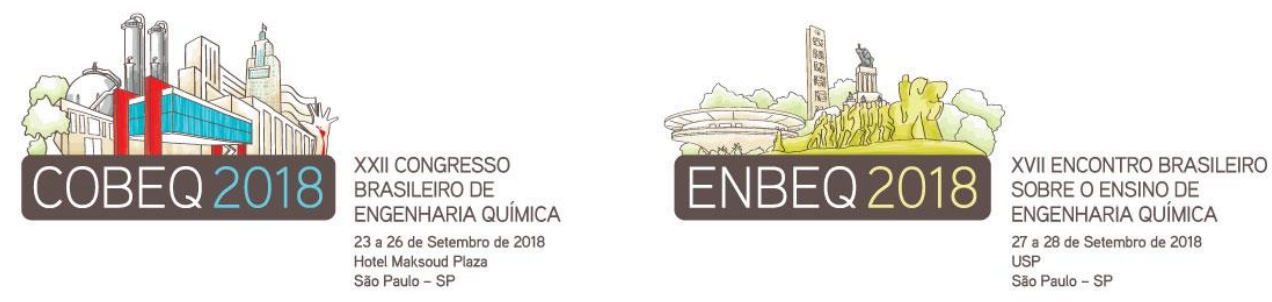

Maiores taxas de redução da concentração de surfactina também foram observadas para temperaturas relativamente elevadas do processo $\left(35^{\circ} \mathrm{C}\right)$, indicando que a adsorção das moléculas do tensoativo é favorecida pelo aumento deste parâmetro.

$\mathrm{Na}$ Figura 2, verificou-se que as maiores concentrações de surfactina na espuma foram obtidas para menores vazões de gás $\left(20 \mathrm{~mL} \cdot \mathrm{min}^{-1}\right)$ devido ao maior tempo de residência das bolhas na coluna de espuma e pela menor quantidade de solução arrastada da coluna de líquido pelas bolhas de gás. Maiores concentrações também foram observadas para temperaturas de operação elevadas. Presume-se que altas temperaturas reduzem a viscosidade da solução, facilitando a drenagem do liquido intersticial da espuma. $\mathrm{O}$ aumento das taxas de drenagem leva a formação de espumas mais secas, aumentando a importância da camada de surfactina adsorvida na interface gás-líquido.

Com os valores de concentração de surfactina e dos volumes do produto de topo, foi possível determinar os parâmetros recuperação e enriquecimento do biossurfactante (Tabela 2).

Tabela 2 - Valores de enriquecimento e recuperação obtidos para o fracionamento de soluções de surfactina em diferentes condições experimentais

\begin{tabular}{|c|c|c|c|c|}
\hline $\begin{array}{c}\text { Vazão } \\
\left(\mathrm{mL} \cdot \mathrm{min}^{-1}\right)\end{array}$ & $\begin{array}{l}\text { Concentração } \\
\left(\mathrm{mg} . \mathrm{L}^{-1}\right)\end{array}$ & $\begin{array}{c}\text { Temperatura } \\
\left({ }^{\circ} \mathrm{C}\right)\end{array}$ & Enriquecimento & $\begin{array}{c}\text { Recuperação } \\
(\%)\end{array}$ \\
\hline \multirow{4}{*}{20} & \multirow[b]{2}{*}{240} & 15 & 31,2 & 97,0 \\
\hline & & 35 & 52,5 & 85,3 \\
\hline & \multirow{2}{*}{700} & 15 & 9,0 & 98,3 \\
\hline & & 35 & 28,2 & 96,0 \\
\hline $40^{(*)}$ & 400 & 25 & $8,2 \pm 1,46$ & $98,0 \pm 0,38$ \\
\hline \multirow{4}{*}{60} & \multirow{2}{*}{240} & 15 & 4,9 & 92,7 \\
\hline & & 35 & 15,5 & 97,3 \\
\hline & \multirow{2}{*}{700} & 15 & 1,9 & 80,5 \\
\hline & & 35 & 4,5 & 96,4 \\
\hline
\end{tabular}

${ }^{(*)}$ experimento realizado em triplicata.

Analisando a Tabela 2, observou-se que os maiores valores de enriquecimento foram obtidos para soluções diluídas (menores concentrações de surfactina) e operando a coluna com baixa vazão de gás e em temperatura relativamente elevada $\left(35^{\circ} \mathrm{C}\right)$. Quanto a recuperação do biossurfactante, foram obtidos valores entre 80,5 e $98,3 \%$.

\section{CONCLUSÃO}

O fracionamento em coluna de bolhas e espuma mostrou ser um processo viável e uma etapa promissora para a separação, concentração e recuperação de moléculas anfifílicas em soluções diluídas. O processo é eficaz quando se opera a coluna com baixa vazão de gás, baixa concentração do biossurfactante e temperatura elevada. Sob condições operacionais investigadas neste trabalho, foi possível obter um produto de topo altamente concentrado em surfactina a partir de soluções diluídas do tensoativo.

\section{REFERÊNCIAS}

BARROS FFC, QUADROS CP, MARÓSTICA JÚNIOR MR, PASTORE GM. Surfactina: propriedades químicas, tecnológicas e funcionais para aplicações em alimentos. Quim. Nova, v. 30, p. 409-414, 2007.

BROWN L, NARSIMHAN G, WANKAT PC. Foam fractionation of globular proteins. Biotechnol. Bioeng., v. 36, p. 947-959, 1990.

SANTANA CC. Adsorptive bubble separation processes as a means of reducing surface active contaminants in industrial wastewaters. Rev. Bras. Eng., v. 5, p. 01-74, 1994. 